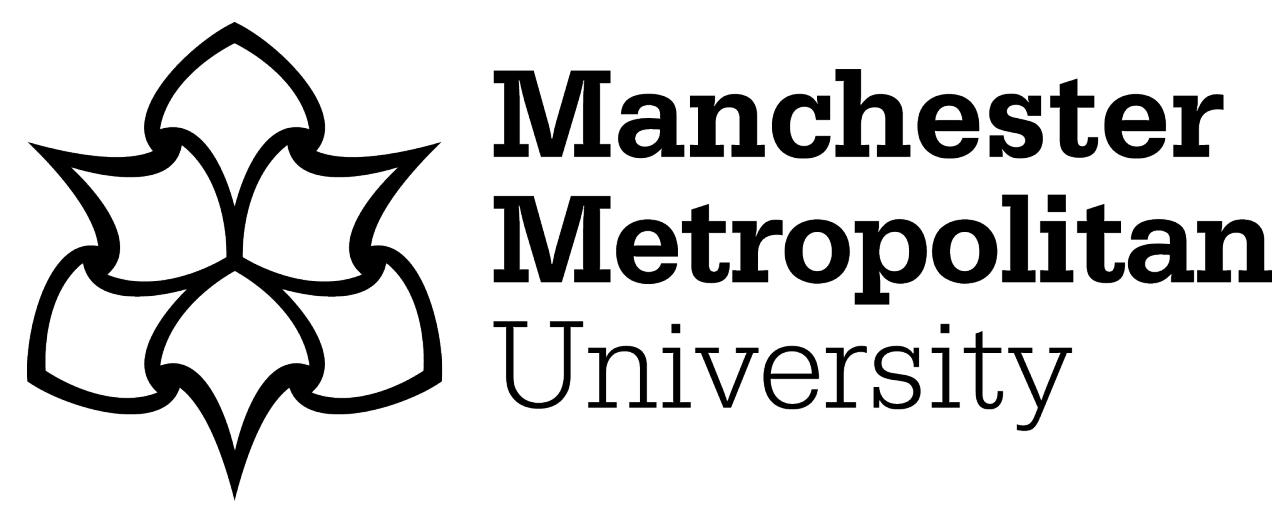

Bjerke, Annette Hessen and Solomon, Yvette ORCID logoORCID: https://orcid.org/0000-0002-2731-8380 (2020) Developing self-efficacy in teaching mathematics: pre-service teachers' perceptions of the role of subject knowledge. Scandinavian Journal of Educational Research, 64 (5). pp. 692-705. ISSN 0031-3831

Downloaded from: https://e-space.mmu.ac.uk/622457/

Version: Accepted Version

Publisher: Taylor \& Francis (Routledge)

DOI: https://doi.org/10.1080/00313831.2019.1595720

Please cite the published version 


\title{
Developing self-efficacy in teaching mathematics: Pre-service teachers' perceptions of the role of subject knowledge
}

\author{
Annette Hessen Bjerke ${ }^{\mathrm{a}}$ and Yvette Solomon ${ }^{\mathrm{ab}}$ \\ ${ }^{a}$ Oslo and Akershus University College, Faculty of Education and International Studies, \\ Postboks 4. St.Olavs Plass, 0130 Oslo, Norway, ORCID 0000-0002-2138-2891 \\ ${ }^{\mathrm{b}}$ Education and Social Research Institute, Manchester Metropolitan University, Brooks Building, \\ 53 Bonsall Street, Manchester M15 6GX, ORCID 0000-0002-2731-8380
}

Corresponding author: annette.hessen@,oslomet.no, Tel. +47 41254388

Co-author: y.solomon@mmu.ac.uk, Tel. +44 (0)161 2472567

\section{Biographical note}

\section{Annette Hessen Bjerke}

Annette Hessen Bjerke is Associate Professor at OsloMet - Oslo Metropolitan University. She has worked in teacher education in Norway for 15 years. She researches in the area of mathematics teacher knowledge, and the development of self-efficacy in teaching mathematics in pre-service teachers. Her work includes development of a measure of self-efficacy in teaching mathematics, using Rasch analysis.

\section{Yvette Solomon}

Yvette Solomon is Professor of Education at Manchester Metropolitan University and adjunct Professor at OsloMet - Oslo Metropolitan University. She researches mathematics teacher development in Initial Teacher Education and in Continuing Professional Development, focusing on teachers' developing practice and pedagogic choices within the context of schooling in Norway and England. She also researches issues of differential access to mathematical literacy and the development of identities of exclusion, particularly in the area of mathematics classroom cultures and pedagogies. 


\begin{abstract}
Two major concerns in mathematics teacher education are the role of subject matter knowledge and the development of self-efficacy in pre-service teachers. This article brings these issues together in an exploration of the interaction between pre-service teachers' perceptions of their subject matter knowledge and their accounts of university and placement experiences as potential sources of self-efficacy. Reporting on a group of ten pre-service teachers in Norway, we explore variations in the ways in which they perceived the role of subject knowledge in relation to experience, particularly 'mastery experiences', over a period of nearly two years. We suggest that recognition of the role of 'understanding why' in mathematics is crucial in the experience of mastery, and that there is a need to focus more on the role of subject matter knowledge in all sources of self-efficacy in teaching mathematics.
\end{abstract}

Keywords: sources of self-efficacy, subject matter knowledge, pre-service teachers, mathematics 


\section{Introduction}

The role of subject matter knowledge in mathematics teaching practice is well-documented, and there is a large body of research examining issues of its depth, importance, nature and categorisation (for example, Ball, Lubienski, and Mewborn (2001); Ball, Thames, and Phelps (2008); Ma (1999); Rowland (2013); Shulman (1986)). Even though Skemp (1976) underlines that having strong knowledge of mathematics does not guarantee 'success' as a mathematics teacher, there are commonly accepted correlations between the quality of teachers' mathematical knowledge and the quality of learning opportunities for students (Goulding, Rowland, \& Barber, 2002; Ma, 1999; Stylianides \& Ball, 2008). In particular, Skemp (1976) adds, teachers who do not possess such knowledge are likely to be limited in their ability to help students develop relational and conceptual understanding.

However, as noted by da Ponte and Chapman (2008), the nature of this knowledge is critical: Shulman (1986) pointed out the difference between knowing that and knowing why, emphasising that a teacher should not only understand that something is so, but additionally also understand why it is so (Shulman, 1986). As Bjerke and Eriksen (2016) found, novice pre-service teachers (PSTs) find 'understanding why' more challenging than 'understanding how'. Consequently, the development of 'understanding why' (or in Skemp's (1976) terms, a relational understanding of mathematics) is often a central goal of teacher education: it is an important component of subject matter knowledge, supporting the development of the ability to deal with contingent moments in the classroom, as identified by Rowland (2013).

The distinction between 'understanding why' and 'understanding how' becomes particularly salient when PSTs enter school placement, a standard component of most programs worldwide (Darling-Hammond \& Lieberman, 2013). Tensions between the research- and theory-driven inquiry-based approaches to teaching mathematics advocated by universities and a test-driven focus on the application of procedural methods in schools are widely reported (Gainsburg, 2012; Nolan, 2008, 2012). In the Norwegian context in which this study took place, investigation of these tensions found that many PSTs in a first-year sample seemed to 'miss the point' of much of the more theoretical input offered in a university teacher education programme, valuing practicebased learning gained from teacher-mentors in school placement more highly than university learning (Bjerke, Eriksen, Rodal, Smestad, \& Solomon, 2013b).

In this article, we explore PSTs' experience of school and university as contexts for learning in more detail, focusing on their perceptions of their mathematical knowledge and its role in their experiences of 'success' and 'failure', basing our analysis on Bandura's (1977) account of selfefficacy applied to teaching mathematics. Self-efficacy captures beliefs about future capacities and what kind of experiences such beliefs build on; for Bandura (1997), knowledge is not a source of self-efficacy in itself, but is mediated by perceptions of experience. Hence, we explore PSTs' 
perceptions of the role of subject matter knowledge in terms of the various sources of self-efficacy available to them: what knowledge do they see themselves as having, or needing to have in the future in order to develop as mathematics teachers?

\section{Sources of self-efficacy at the intersection of experience and knowledge}

Self-efficacy is a person's judgement of his or her abilities to successfully execute a course of action (Bandura, 1977), a future-oriented belief about the level of competence one expects to show in a specific situation. Despite indications that teachers' self-efficacy impacts on student outcomes (Woolfolk \& Hoy, 1990), studies investigating the development of self-efficacy in mathematics teaching are relatively rare (Charalambous, Philippou, \& Kyriakides, 2008; Klassen, Tze, Betts, $\&$ Gordon, 2011). Even fewer are directed at PSTs, despite indications that teacher self-efficacy develops mainly during teacher education (Charalambous et al., 2008; Hoy \& Spero, 2005). Mathematics teaching is an especially interesting context, since PSTs often express doubt about their self-efficacy in mathematics (Gresham, 2007), while the concepts of self-efficacy in mathematics and self-efficacy in teaching mathematics appear to be closely related (Briley, 2012; Phelps, 2010).

Bandura (1977) described four sources of experience that may contribute to the formation of efficacy beliefs. Mastery Experiences relate to perceptions of previous success in performing a particular task, while Vicarious Experiences are situations in which one watches another person successfully perform the behaviour one is contemplating. Verbal Persuasion involves feedback from others that aims to enhance a person's belief that they have the capability to perform a given task at a certain level. Finally, Physiological and Affective Responses denote somatic states such as anxiety or pleasure that can be a source of efficacy information.

Research on sources of self-efficacy in teaching tends to focus on the relative importance of each source (Brand \& Wilkins, 2007; Charalambous et al., 2008; Poulou, 2007; Wah, 2007). For example, Charalambous et al.'s (2008) work suggested that vicarious experience and verbal persuasion were crucial: they reported that mentors influenced PSTs' efficacy beliefs by modelling teaching and providing feedback, and through the latent messages that their behaviour conveyed (Charalambous et al., 2008, p. 140). However, Brand and Wilkins (2007) suggest that mastery experiences are the predominant source, and may additionally in fact mediate the other three sources. Morris, Usher, and Chen's (2016) extensive review of 82 empirical studies focusing on measuring and conceptualising sources of teacher efficacy reveals that mastery experiences $(\mathrm{N}=$ 73) were the most commonly assessed source across the 82 studies, followed by vicarious experiences $(\mathrm{N}=58)$, social persuasion $(\mathrm{N}=56)$ and physiological and affective states $(\mathrm{N}=43)$. The predominance of attention given to mastery experience is not surprising given that Bandura (1997) rates this as the most powerful source of efficacy information. Extending the view, Morris et al. (2016) raise an interesting issue which introduces a further complexity: early student teaching experiences tend to raise PSTs' self-efficacy in teaching, while the first year as a classroom teacher 
is reported to decrease it (Hoy \& Spero, 2005). To illustrate their point, Morris et al. (2016) draw on an example from Morris and Usher's (2011) study of 12 teaching award-winning professors who were asked how they developed a sense of teacher efficacy. Their answers were easily interpreted as mastery experiences, but when pressed to elaborate on how they knew they had done well, their teacher efficacy was also informed by verbal persuasion. Therefore, what initially seemed like mastery experiences in the form of perceptions of one's past teaching experience were derived from a variety of sources (Morris et al., 2016). Taken together, these results collectively illustrate that teachers reflect on many different sources when providing such general appraisals of their past teaching performances (Morris et al., 2016). This issue, together with the fact that research shows contradictory results on the relative importance of the sources, demonstrates the need to recognise complexity when investigating sources of self-efficacy in teaching mathematics.

Previous research on teacher efficacy development has tended to focus on school placement because it provides opportunities to investigate mastery experiences (Pfitzner-Eden, 2016). However, given the complexities revealed by Morris et al. (2016), we suggest that exploring the nature of the sources themselves in terms of PSTs' perceptions of the role of knowledge in the various contexts in which they learn is central to understanding the development of self-efficacy in teaching mathematics. Thus we are concerned less with the significance of location of sources than with the way in which PSTs perceive and draw on their experiences in them as they develop their view of the knowledge that they have, or need to have, in order to teach well. Addressing Wyatt's (2014) conclusion from his review of previous research that poor conceptualisations of the role of knowledge have obscured understandings of how teachers' self-efficacy beliefs develop, and the sparseness of research on the role of mathematical knowledge in teacher efficacy (Klassen et al., 2011), we pose the following research question:

How do PSTs draw on sources of self-efficacy, and what is their perception of the role of subject matter knowledge in such sources?

\section{Methodology}

The PSTs in this study were enrolled in a four-year programme for primary school teachers (grades 1-7, ages 6-13) in the largest teacher education institution in Norway, producing about 220 new primary and middle school teachers each year (120 and 100 respectively). The generalist programme includes a 30 credits compulsory course in mathematics pedagogy spanning the first two years, with an optional further course in the third year. The mathematics teacher educators promote and model teaching focusing on explanations, understanding and connected knowledge.

All 191 PSTs in the cohort of 2013 (mean age 22.5 years, 20\% men) were asked to indicate their willingness to be interviewed as part of a survey questionnaire used in a larger study of PST development. While many ticked the box to indicate willingness, fifteen wrote additional comments emphasising their interest. Since retention over the course of repeated interviews was important, these fifteen were invited to participate, and ten of these eventually arrived for their 
first interview with the first author of this article.

PSTs undergo a total of 30 days of placement organised into three-week blocks in each of the two first years. Participants were interviewed before and after each of their first three school placements (six interviews with each participant), giving a total of fifty-eight interviews (one PST withdrew after four interviews).

The overall intention of the semi-structured interviews was to explore PSTs' accounts of their learning in university and school placement, focusing on their perceptions of the nature of subject matter knowledge and its role in their experiences of learning on the teacher education programme and of teaching mathematics in their placements. The key topics for particular interviews were:

- what it means to be a mathematics teacher [interviews 3, 4 and 6]

- learning in school placement [interviews 2, 4 and 6]

- learning at university, and how this does or does not connect to school placement [interviews 3 and 5]

- PSTs' focus as a developing teacher at university and in placement [interviews 4 and 5]

- changes and developments in PSTs' relations to mathematics [interviews 1,5]

- PSTs' development as mathematics teachers and what has contributed to this [interviews 5 and 6]

- what kind of mathematics teacher do PSTs want to be [interview 6]

A number of ethical issues arise in research of this sort. First, it is important to note that the first author of this article has been a mathematics teacher educator for more than a decade in the institution in which this particular research was conducted. Clearly this raises issues of power in that interviewees might feel obliged to be positive about their teacher education programme. Second, the nature of the interview topic meant that interviewees would inevitably refer to other people in addition to those voluntarily participating in the study. Finally, there is the question of intrusion into interviewees' everyday life and their relationships to their peers and mentors.

With respect to the first of these issues, the study was designed to take place at a time when the first author was not a tutor on the programme. Nevertheless, the fact that the interviewees knew about their former role could still lead to power imbalance in the interviews. This issue, and those of intrusion and respect for third parties, was addressed through the formal ethics approval processes of the national Norwegian Social Science Data Service, which prioritises participants' interests in all university research projects. Participants were provided with full information about the project, and consent forms which emphasised their right to withdraw. They were assured of complete confidentiality; nothing would be passed on to peers, tutors, mentors or programme leaders. The first author also took care to be available after the interviews to discuss any concerns that the interview topics might have raised.

A further implication of the first author's role in the institution is the presence and effect of researcher subjectivity in the design, conduct and analysis of the study (Peshkin, 1988), and the 
need for a conscious awareness of one's own preconceived understanding and expectations. In this particular context, these include a partly research-based assumption that deeper mathematics knowledge leads to increased self-efficacy. More importantly, informal assumptions about "the typical PST" and concerns that "they don't know enough mathematics" and "don't get what we are trying to teach them" are a threat to the (unachievable) ideal of objectivity. It is important to confront the preconceived understandings and assumptions which are inevitable in researching one's own field of practice; as joint authors we dealt with such subjectivities through our explicit awareness of their existence and an ongoing attempt to question such preconceptions. In addition, the second author was able to take a more critical perspective as an outsider who had never been engaged in mathematics teacher education in Norway. Finally, our theoretical framing and its associated analysis process also provided a means of introducing rigour through systematic analysis.

The interviews were transcribed in full in their original language (Norwegian) and analysed in three steps. Step one involved a process of consistent coding (Mason, 2014) that entailed reading and re-reading the transcripts of the first post-placement interview (interview 2) with each of the ten PSTs in order to identify all references to the role of subject matter knowledge in university and school placement contexts, noting connections to experiences of success and failure, and PSTs' explanations of what contributed to these experiences. We chose interview 2 as the starting point since this was the first opportunity to include references to placement in our coding. In step two, we moved to a process of cross-sectional indexing involving a sequential reading of each of the ten PSTs' six interviews, noting similarities in individual trajectories. In order to answer the first part of our research question ("how do PSTs draw on sources of self-efficacy?"), in step three, we took a more contextually bounded, holistic case study approach in which we applied a layer of analysis in terms of references to Bandura's (1977) four sources of self-efficacy, Mastery Experiences, Vicarious Experiences, Verbal Persuasion and Physiological and Affective Responses, which we operationalised in accordance with Bandura's definitions as follows:

Mastery Experiences:

Vicarious Experiences:

Verbal Persuasion:

Physiological/Affective Responses:
References to success in teaching tasks in relation to underlying pedagogic/subject matter knowledge.

References to seeing another person (e.g. a peer or mentor) successfully undertaking a teaching task which the PST is planning.

References to positive feedback from others, especially from mentors.

References to somatic states such as anxiety or pleasure in relation to performing a teaching task. 
This enabled us to focus on how PSTs connected experience and the role of subject matter knowledge, which was important for the second part of our research question ("what is their perception of the role of subject matter knowledge in such sources?"). Such a reading of holistic 'units' is helpful when trying to produce an explanation of processes, experiences and practices (Mason, 2014). This approach enabled us to both note possible patterns across the group, and to note and explore in more depth one PST who acted as a contrasting case in comparison to the other nine participants, thus highlighting particular aspects of such patterns.

To ensure validity, passages identified in the three steps of analysis were translated into English and discussed between the two authors (one native Norwegian speaker and one native English speaker), often resulting in a re-reading of the original transcripts. Extensive discussions between the authors ensured that the original meaning was captured.

In presenting our analysis, we are necessarily limited to illustrative quotes only. In order to ensure that such quotes are representative across the group, we have aimed to stay close to our operationalisations of Bandura's sources, and to ensure that all PSTs are represented, including quotes that do not fit the general pattern. As noted above, one particular PST, PST9, emerged as taking a different trajectory to the other nine participants. Including her case supports the rigour of our analysis but also puts the other cases into sharp relief, drawing attention to important issues in their development.

\section{Connecting knowledge and experience}

In this section, we present our analysis focusing on how our ten case study PSTs connected knowledge and experience as they developed self-efficacy as mathematics teachers through the first two years of their training. Clearly, we would expect their ideas to develop over time, but our focus here is on the nature of their perception of the role of subject matter knowledge in their experiences of success and failure as sources of self-efficacy. We see a general pattern among the majority of the PSTs in terms of a growing recognition of the usefulness of the theoretical content of their university course in the sense of subject matter knowledge, in tension with an earlier prioritising of the value of practice - and the affective responses this can bring - in placement. They begin to resolve this tension during the second year, connecting knowledge and experience as part of developing a sense of future mastery. However, not all the PSTs followed this trajectory, and one - PST9 - often presents a contrasting case, which we discuss later on in the article.

\subsection{The novice phase: The challenge of theory}

In the early interviews before the second placement (interviews 1-3), the PSTs tended to talk about mathematics teaching in terms of their ability to get through a lesson in the sense of having "survived". Thus references to the role of university input focused on the extent to which it provided them with specific skills and competences that they felt they needed in placement, and consequently many commented that there were 'gaps' in the programme. For example, when 
PST1 was asked if she felt well prepared for the upcoming school placement, she answered:

They [the pupils in her placement class] are about to learn the clock, and this isn't a topic we have talked about in our maths classes [at university], so in that sense I don't feel well prepared (PST1, I3)

Maintaining a 'tips and tricks' focus despite the fact that university teachers design the course with a view to supporting a deeper conceptual understanding which can then be applied in practice, the PSTs reported that what was useful about university was its input on specific activities which they could copy:

...I feel I have learned a lot, a lot that is relevant [at university] ...especially the work on tips and tricks, I find that very handy (PST4, I3)

I have picked up tips and tricks which I feel is worth remembering (PST5, I3)

This focus meant that their accounts of successful teaching tended not to relate to underlying connections within mathematics knowledge, but more to individual lessons as affective sources of self-efficacy. What they held up as the epitome of being a successful mathematics teacher at this stage tended to relate more to supporting pupils by making mathematics accessible, and their accounts were embedded in references to an affective response on these occasions:

You get happy and motivated when you manage to teach someone something, because that is after all, if you ask me, the point of being a teacher (PST3, I2)

They often described such success in terms of their ability to engage pupils, and make mathematics exciting and fun:

A good maths teacher is one that enables pupils to understand ... one has to be engaged in order to enable the pupils to engage... It's also important to make mathematics exciting (PST2, I3)

[A mathematics teacher] has to be a person who is creative ... who can make it practical ... be engaging and make the pupils realise how much fun it is to solve tasks they have struggled with (PST3, I3)

Thus experiencing and evoking positive affective responses seemed to be a major contributor to most of the PSTs' sense of self-efficacy at this stage. However, while PST9 also focused on affect, her outlook was far less positive; she simply hoped to

...make them understand that it [mathematics] might be alright, there are worse subjects (PST9, I3)

This comes from a PST who, by her own account, was an above average performer in mathematics at school.

Nevertheless, while most PSTs equated knowledge needed for teaching and 'tips and tricks', some made reference to mathematics knowledge and its role in teaching, acknowledging that there was 
more to learn. For example, when specifically asked if he had learned any useful mathematics at university, PST5 distinguished between his knowledge of mathematics for himself and the kind of knowledge needed to explain to others:

I feel I know it [mathematics] myself, but it's a totally different level when it's about presenting it to others and teaching them how to do it (PST5, I3)

Moreover, PST6 talked about the importance of the core, and the need to know the basics in mathematics. He linked this to his teacher education programme:

We have a new lecturer in mathematics ... I think he's very good ... He's very concerned with knowing the basics first ... start with what you might think you know but that you maybe didn't really know (PST6, I3)

While these comments show awareness of a missing knowledge base which they sense they need to develop in order to gain mastery experiences, PST9 was concerned to find a 'fit' between her existing way of learning mathematics and the teaching at university. For example, in the period immediately before interview 3, university teaching had focused on 'The Family of Quadrilaterals'. The PSTs had investigated how the different classes of quadrilaterals connect to each other, and the fact that, for instance, a square meets all the requirements of a rectangle, and hence can be described as a rectangle. PST9 expressed confusion about this approach, and was critical of the university mathematics curriculum:

I'm getting more and more confused ... It's a bit uncomfortable to know that I have to teach things I didn't learn myself when I went to school ... It's hard to learn something that doesn't make sense. I don't want to talk about a square as a rectangle (PST9, I3)

Although they recognised that a different mathematics for teaching existed, most PSTs did not prioritise this aspect of teaching, and indeed PST9 actively resisted it. Consequently, she did not see university as contributing to her learning, and it disrupted any perception of how she could experience mastery in school placement. Instead, she decided to neglect university input and rely heavily on positive affective experiences in her placement:

Learning by doing ... it's totally different in school placement, it can't be compared to what's presented to us at university (PST9, I2)

PST9 was clearly challenged by theory in terms of the university's focus on 'understanding why'. She relied heavily on placement learning early in her training, avoiding any consideration of the role of subject matter knowledge in these experiences. Other PSTs were more willing to engage with the university approach, but were also seeking isolated tips and tricks as a means of building a self-efficacy in the classroom which was largely based on their own and their pupils' affective responses. As they experienced longer placements, they increasingly emphasised learning in placement, as we show in the next section. 


\subsection{The intermediate phase: An emphasis on practice}

Interviews 4 and 5 took place immediately after the PSTs' second school placement, and before the third. Analysis suggested that the second placement presented them with opportunities to develop self-efficacy based on a variety of experiences which tended to lead them to prioritise practice over theory. Although some PSTs recognised the value of university input, there was also criticism of it and a turn to mentor feedback as a more dominant source of self-efficacy. PST6 maintained his earlier stance on the value of university teaching, noting the contrast between university mathematics and the upper secondary school mathematics he had been taught:

The knowledge in upper secondary ... is very instrumental ... Here [at university] you get the opportunity to work with mathematics, both learning things and practicing how to teach it. You pick up a certain way of talking about mathematics (PST6, I5)

PST4 made a similar point:

... you have to work with mathematics in a different way, more practically [at university]...

In upper secondary ... it was more about formulas and cramming. (PST4, I5)

However, overall, placement experience seemed to outweigh this view, leading to criticism of the teaching at university in the form of a contrast between a sense of 'real teaching' in school versus what PSTs described as a more superficial approach to teaching at university. PST3 saw university and school placement as "two different worlds", while PST6 went on to say that it was important to

... be critical of what we learn here at university ... be critical of how university chooses to do things. I think that's healthy, because it might be easy to think that university has a recipe for what teacher education should be ... It's too fragmented, we learn too much just because it can be checked off a list - 'This is a pre-service teacher. When he has ticked off all these issues, then he is a competent teacher' (PST6, I5)

Moving away from a reliance on tips and tricks, PSTs drew on verbal persuasion as a source of self-efficacy in the form of feedback from mentors, leaving no trace of a focus on subject matter knowledge in these sources. For some PSTs, just the fact of praise boosted their confidence:

When I do well, it's good to be praised [by the mentor]. It gives me self-confidence (PST8, I4)

However, more PSTs described a shift from valuing mere praise to wanting formative constructive feedback, suggesting a parallel shift in what contributed to verbal persuasion as a source of selfefficacy:

In the beginning, I needed to hear that I was on the right track ... but by the end of the placement, I needed supervision more when I felt that things didn't go as planned (PST4, I4)

I do often realise what went wrong, but it's good to let her [the mentor] suggest what to do about it ... I prefer constructive criticism rather than praise (PST3, I4) 
I like to talk about situations where things didn't go as planned ... that's when you really learn (PST6, I4)

PST9 also gained a lot of confidence from placement, describing how she felt at home in school ("I felt we were one of the teachers" (PST9, I4)). Although in interview 3 she had been 'dreading' negative feedback as fundamentally damaging to her career aspirations, she enjoyed getting feedback now. However, unlike some of the other PSTs who were less convinced by purely positive feedback, attributions of success in placement were crucial:

It was nice to get feedback after lessons, because [the mentor] pointed out positive things ... I need to show that I'm meant to be here ... I have a feeling that I'm not very good at written tasks [at university]... practice is my strong point ... (PST9, I4)

In contrast to the other PSTs, who despite their criticism of university did see the potential importance of its contribution to the development of their subject matter knowledge even if they did not give it priority, success in practice (in the form of positive messages from verbal persuasion) was thus PST9's sole source of self-efficacy. As the next sections show, this continued to be the case.

\subsection{The more experienced phase: recognising the role of subject matter knowledge}

By interview 6, after their third placement, the PSTs appeared to have made a significant shift towards a new recognition of the role of subject matter knowledge in the actual practice of teaching. PST 5, for example, expressed the role of a deeper understanding of mathematics in teaching even at elementary level:

[I have] gained a deeper understanding in mathematics ... I thought - elementary school mathematics - that's not a problem! But it's so much more than plus and minus ... all the things that lie behind it, that's very important (PST5, I6)

For PST4 this contributed to a new confidence as a practitioner:

I feel more secure standing in front of a class, and much less nervous. [Now] I feel I'm so secure in this role that I can see the pupils more when I teach, instead of just being concerned with what I am doing on the blackboard ... It's also easier to follow the lessons [given at university], I see what's important sooner ... (PST4, I6)

We can sense that new knowledge contributes to these affective responses. She continues:

I think it's always a challenge to see how the pupils think ... If they don't get the basics, the consequences are huge (PST4, I6)

Capturing the need for a more connected understanding of elementary mathematics, PST7 noted the fine-tuning required, and the challenge of putting this into practice:

We've realised that decimals, fractions ... are very hard to explain in a simple way... For instance, when you have to teach fractions, then you realise that there are some things that 
need to be in place before you start teaching ... explaining plus and minus to a $1^{\text {st }}$ grader that's very complicated! (PST7, I6)

These experiences of challenge led PSTs to realise their need for a different kind of knowledge. It is as if they now saw how having a limited grasp of the underlying principles needed in order to explain in 'a simple way' would prevent mastery experience sources of self-efficacy in teaching mathematics.

In contrast, PST9 struggled to work with this complexity and continued to rely on guidance from her mentor:

My mentor taught me how to explain to children how to calculate and why they [the teachers in the school] did it this way (PST9, I6)

She gave several examples of what she meant by this: "when to say 'digit', when to say 'number', when to say 'decimal' rather than 'decimal number"' (PST9, I6). Instead of learning about these issues in the university context, she relied heavily on copying her mentor, trying to remember 'when to say what', as a vicarious source of self-efficacy.

However, as a result of their new reflections, the majority of PSTs felt in a position to make judgements not only about their own teaching, but also that of more experienced others. Some PSTs shifted from unalloyed appreciation of their mentors' input to a new criticality of both their mentors and other teachers in their placements. Here PST1 reflects on the shortcomings of a mathematics teacher she observed, underlining his lack of mathematics knowledge:

I think the mathematics teacher was bad ... he was extremely un-pedagogical and bad at maths... He wasn't [just] imprecise, he was wrong... the poor teacher who will have to undo the misconceptions the pupils get from this particular teacher (PST1, I6)

Their new critical and reflective outlook, together with their recognition of what they had learned at university and how it applied to teaching as part of their developing repertoire, is summarised in PST10's assessment of her developing sense of self-efficacy as a teacher, grounded in mastery experiences in which success is based on her utilisation of university knowledge which she feels stands her in good stead for what might come up:

I feel more secure in the role as a teacher ... I know how to talk and how to prepare ... [it's] all due to a better foundation in mathematics ... and how the pedagogy courses [at university]... make it all connected (PST10, I6)

Statements like this underline how subject matter knowledge appeared to be connected to mastery experience, and related affective responses. However, not all PSTs made this connection between theory and practice. In interview 5, in the run-up to her third placement, PST9 expressed a lack of self-efficacy about her ability to teach, apparently indicating a realisation that she lacked subject matter knowledge. But, unlike PSTs 5 and 7 above, she still did not recognise the need for subject matter knowledge in the lower grades: 
A part of me wants to be [a mathematics teacher]... But I don't know if I'm capable of teaching this subject. I know I can make it in the lower grades, but I don't know if I'm capable in seventh grade because I struggle so much myself [with the subject matter knowledge] (PST9, I5)

After the third placement, in interview 6, she was still drawing on guidance from her mentor as a source of vicarious experience in the absence of an ability to make her own judgements about how and what to teach:

My mentor taught me how to explain to children how to calculate and why [the teachers in the school] did it this way (PST9, I6)

Describing a highly context-based sense of self-efficacy, she explained that she managed her mathematics teaching by preparing which calculations to do on the blackboard, doing them herself before the lesson, and thinking through how to explain every step in a way that pupils would understand. She worried about the demands of this strategy:

I'm afraid it will be too tough, that I'll fall badly behind and almost drown (PST9, I6)

In contrast to the other PSTs' development, her account of how she learned to be a mathematics teacher remained heavily dependent on sources in school placement against a background of insecurity in her mathematics knowledge:

That's where I learn everything; that's where I learn to become a teacher (PST9, I6)

Unlike the other PSTs who, after three periods of school placement, had begun to see university input as central to their development as mathematics teachers, for PST9 it was something to simply get over and done with:

I'll try to survive the last years in teacher education and get through it (PST9, I6)

She thus appeared to be 'stuck', relying on affective responses, verbal persuasion and vicarious experience as sources of self-efficacy gained in her placement, which prevented her from further development in terms of university input and mastery experiences.

\section{Discussion}

Our analysis identifies a general pattern among the majority of the PSTs in terms of a shift in sources of teacher efficacy from early stages where they recognise the potential and the challenge of theory but nevertheless emphasise practice and a reliance on skills picked up in placement, to a later stage when they connect theory and practice and describe self-efficacy in terms of control of subject matter knowledge as an important part of the sources they draw on. Our research question asks how PSTs draw on sources of self-efficacy, and what their perception of the role of subject matter knowledge in such sources is. Building on the previous literature on PSTs' prioritisation of placement learning (Allen, 2009; Gainsburg, 2012; Nolan, 2012), we were particularly interested in their accounts of the contribution of university and school placement to their teaching 
experience. As we have seen, their sense of self-efficacy was characterised by an early need for tips and tricks, which presented opportunities to experience an affective source of self-efficacy. The university's perceived lack of focus on 'tips and tricks' in comparison to their abundance in school placement led PSTs to draw more heavily on experience in this context.

Having gained some more placement experience, they began to draw on verbal persuasion from mentors in terms of individual lessons that they felt had gone well. In this sense, the PSTs tended to relate to teaching in terms of where they acquired skills and set lesson strategies which would enable them to be successful in placement, with little concern for the principles and subject matter knowledge which might underlie such practices. Subject matter knowledge did not have a role in sources of self-efficacy at this point. They ignored the subject matter knowledge taught at the university, finding confidence instead in copying mentors. However, simple verbal persuasion soon lost its power as a source of self-efficacy and was replaced by a desire for constructive verbal persuasion alongside mastery experiences, and the opportunity to reflect on the connections between theory and practice which this afforded. This appeared in a new criticality of both their mentors and other teachers in their placements in which they drew on university input on teaching mathematics for understanding and its implications for acting contingently.

Towards the end of the research period, the PSTs began to draw more heavily on mastery experiences that were associated with university subject matter knowledge. In time they came to recognise the roles of both university and school placement in their development in terms of the connection between their grasp and use of subject matter knowledge and the experience of success and failure in placement, some even commenting on 'the obvious role of subject matter knowledge'.

However, as we have shown, not all our PSTs followed this trajectory. The contrasting case of PST9 indicates how this shift may be disrupted by an over-reliance on a single source, and illustrates the results of an on-going rejection of university theory as too challenging or irrelevant. This case highlights the difficulties arising when the connections between university and placement learning remain unclear, leading to an over-reliance on 'scripted teaching' without reflection. PST9's assessment of success or failure related only to whether or not she had been able to execute her lesson plan and her associated feelings after the event; as her strategy for preparation demonstrates, she was unable to learn from failure beyond adding even more exhaustive preparation and specific topic-based techniques to her repertoire. PST9 was thus 'stuck' in her emphasis on context-bound skills where verbal persuasion, vicarious experience and affective responses played a crucial role in her sense of self-efficacy, detracting from the role of subject matter knowledge. Without the balance between the sources and the growing awareness of subject matter knowledge in these sources that the other PSTs seemed to evolve, PST9's reliance on placement learning resulted in a lack of the kind of self-efficacy that accrues from reflection on learning and the recognition that theory can be manipulated in practice. In contrast to the other PSTs, her inability to engage with university support in accessing the underlying principles and connections in the mathematics she needed to teach meant that while her sense of 'in the moment' 
success in placement provided her with a source of (fragile) self-efficacy, she was unable to gain access to a longer-term complementary source gained from a sense of connection to knowledge which can be used contingently in non-scripted situations.

For the majority, however, the newly discovered connection between university and placement learning in terms of their engagement with university theory and their ability to manipulate it in practice, enabled them to build towards a sense of self-efficacy in teaching mathematics in the sense of their access to a knowledge focusing on 'understanding why' (Skemp, 1976) and its role in dealing with the complexity of practice - for instance, the contingent moments which arise (Rowland, 2013). The PSTs' later descriptions of success and failure suggest that not only have they begun to value university input and its potential for application to practice, but that their valuing of placement is more grounded in the insights it gives them into why subject matter knowledge is important.

In answering our research question, we note some of the obvious limitations of a longitudinal study. The PSTs who participated in this series of six interviews over nearly two years were selfselected and very eager to participate, and only one of the original ten withdrew. This could be indicative of special characteristics of this group that are not generalizable. Moreover, as with any longitudinal study, the benefits of going beyond a snapshot view need to be set against the possibility that involvement in the study changed these PSTs and caused them to reflect more on their subject matter knowledge. In order to offset this possibility, we have been as rigorous as possible in our analysis. In particular we tried not to force the data into particular categories, but to be open to variations in PSTs' development.

\section{Conclusion and implications}

This study has contributed to the field in both theoretical and practical ways. As noted above, among the four sources, research reports that mastery experience generally has the strongest effect on self-efficacy (e.g., Bandura (1997)), and PSTs' field experiences, such as in-school placement, are the most likely opportunity for developing mastery by practicing the skills and actions of a teacher (Moulding, Stewart, \& Dunmeyer, 2014). Previous research on teacher efficacy development has tended to focus on school placement because it provides opportunities to investigate mastery experiences (Pfitzner-Eden, 2016). Our approach calls for a shift of focus in research which aims to understand mathematics teacher development by drawing attention to the role of PSTs' reflections on their own subject matter knowledge in the sources of self-efficacy in teaching mathematics.

Practically, the approach taken in this article is in many ways guided by Wheatley's (2005) call to make research on teacher efficacy more applicable in teacher education. Building on a well-argued conviction that teacher efficacy is an important teacher characteristic (Woolfolk \& Hoy, 1990) with many positive consequences, our aim has been to focus on sources of self-efficacy in a way that enables us to conceptualise the role of subject matter knowledge in PST development, and to 
investigate more closely what is easily interpreted as mastery experiences (as noted by Morris et al. (2016)). Bearing in mind the caveat above concerning the limits to generalizability from our sample, our analysis raises a number of implications for teacher education in the context of the current literature and our own experience of professional practice.

\subsection{Implications}

In the research reported in this article, we see that in our sample, the PSTs' accounts of success and failure were most often made with reference to school placement. Since mastery experience appears to be the most powerful source of efficacy beliefs (Allen, 2009; Bandura, 1997) and the most important source in improving teachers' knowledge (Morris et al., 2016), it is appropriate to ask if it is only possible to draw on this source during school placement. There are pedagogies that are less concerned with where PSTs' training takes place, and more with what PSTs are helped to learn and how to learn it (Forzani, 2014). Turning for instance to the body of research on core practices, these approaches provide opportunities to experience mastery in the university, which might raise PSTs' self-efficacy and offer opportunities to reflect immediately after such experiences. We propose that giving PSTs teaching tasks for smaller groups of peers, or presenting a new mathematics theme, or other similar activities, may be one way to situate mastery experiences which focus on subject matter knowledge in university teaching.

This research has additionally highlighted the importance of subject matter knowledge as a focus of reflection on experience, suggesting that teacher education should provide more opportunities for such reflection, both in school placement and at university. Our findings add to Bandura's (1997) emphasis on mastery experience as the most powerful source of self-efficacy by illustrating the need for teachers to reflect on what actually constitutes mastery in a particular context, and how it relates to subject matter knowledge. When we look at how sources are played out, we see that PSTs' perception of subject matter knowledge directs their onward trajectory. Again, core practices take subject matter knowledge and context-specific learning goals for students as their point of departure (Forzani, 2014), and suggest ways forward. There was little evidence of vicarious experience which focused on subject matter knowledge in the data, but when PSTs have limited previous experience as in the early stages in this study, vicarious experience has substantial influence on self-efficacy although it is still unclear what its exact role is (Moulding et al., 2014). Teacher education could aim to offer more vicarious experience where subject matter knowledge explicitly contributes to the success of a significant other.

Our analysis similarly showed no evidence of verbal persuasion that explicitly focused on PSTs' subject matter knowledge and its role in teaching, although its presence in constructive feedback was implicit. This raises the question as to how often PSTs receive feedback on their subject matter knowledge (or lack of it), at either university or during school placement. Both teacher educators and placement mentors could aim to highlight the role of subject matter knowledge. Given the clear importance of verbal persuasion in placement, this may be a crucial addition to mentor 
training, since mentors are perhaps the most significant others at times.

Bandura (1997) argues that self-efficacy is central to the exercise of human agency. In this view, we can argue that teacher education should provide experiences that enable learners to become more autonomous and independent in their thinking and acting - raising PSTs' self-efficacy in teaching mathematics in the context of this article. Looking at the main group of PSTs in this study, we might say that their teacher education programme is quite successful in achieving this despite (or because of) the problems they encounter. However, as the case of PST9 shows, this is not necessarily true of all and we should consider her not just as an exception in the small group of PSTs interviewed here, who may indeed not themselves be representative of the wider student population, but as a representative of a potentially significant group. As teacher educators ourselves, we draw on our professional experience of encountering students such as PST9 who are seen as "weak". The analysis here offers a new way of recognising the agency of such PSTs. As we have seen, PST9 is an example of someone who seems unwilling to reflect on the role of subject matter knowledge, or to engage in the 'new dimension' of mathematics - teacher education demands that she engage with being able to explain why it makes sense to use rules, not only how to use them. Based on the wide literature highlighting the impact of a lack of subject matter knowledge in pre-service and practicing teachers (Goulding et al., 2002; Ma, 1999; Stylianides \& Ball, 2008), we suspect that there are many PSTs like her in different teacher education programmes, struggling to take in what teacher education has to offer. Our analysis has contributed to a deeper understanding of such lower-performing PSTs who may be seen as hopeless cases because "they don't know any maths". We have seen that while PST9's subject matter knowledge is indeed an issue, her experience and perception of this situation, and how she dealt with it, is equally important. Remembering that she was an above average performer at school, we would argue that she has the ability to develop a command of the subject matter knowledge needed, but she is resistant to engaging with a new kind of mathematics, as she sees it. Her case presents teacher educators with a challenge in how they might enable prospective teachers like her to meet the challenge of the focus on 'understanding why', and so ensure that teacher education contributes to a positive development of self-efficacy in teaching mathematics, rather than simply being something to 'survive'.

\section{References}

Allen, J. M. (2009). Valuing practice over theory: How beginning teachers re-orient their practice in the transition from the university to the workplace. Teaching and teacher education, 25(5), 647-654. doi:10.1016/j.tate.2008.11.011

Ball, D. L., Lubienski, S. T., \& Mewborn, D. S. (2001). Research on teaching mathematics: The unsolved problem of teachers' mathematical knowledge. In V. Richardson (Ed.), Handbook of research on teaching (4th edition ed., pp. 433-456). New York: Macmillan.

Ball, D. L., Thames, M. H., \& Phelps, G. (2008). Content knowledge for teaching: What makes it special? Journal of Teacher Education, 59(5), 389-407. 
Bandura, A. (1977). Self-efficacy: toward a unifying theory of behavioral change. Psychological review, 84(2), 191-215.

Bandura, A. (1997). Self-efficacy: the exercise of control. New York: Freeman.

Bjerke, A. H., \& Eriksen, E. (2016). Measuring pre-service teachers' self-efficacy in tutoring children in primary mathematics: an instrument. Research in Mathematics Education, 18(1), 61-79.

Bjerke, A. H., Eriksen, E., Rodal, C., Smestad, B., \& Solomon, Y. (2013b). A tripartite cooperation? The challenges of school-university collaboration in mathematics teacher education in Norway. Proceedings of the International Groups for the Psychology of Mathematics Education, 2, 89-96.

Brand, B. R., \& Wilkins, J. L. (2007). Using self-efficacy as a construct for evaluating science and mathematics methods courses. Journal of Science Teacher Education, 18(2), 297-317.

Briley, J. S. (2012). The relationships among mathematics teaching efficacy, mathematics selfefficacy, and mathematical beliefs for elementary pre-service teachers. Issues in the undergraduate mathematics preparation of school teachers, 5, 1-13.

Charalambous, C. Y., Philippou, G. N., \& Kyriakides, L. (2008). Tracing the development of preservice teachers' efficacy beliefs in teaching mathematics during fieldwork. Educational Studies in Mathematics, 67(2), 125-142.

da Ponte, J. P., \& Chapman, O. (2008). Preservice mathematics teachers' knowledge and development. In L. D. English (Ed.), Handbook of international research in mathematics education (pp. 223-262). New York: Routledge.

Darling-Hammond, L., \& Lieberman, A. (Eds.). (2013). Teacher education around the world: Changing policies and practices. New York: Routledge.

Forzani, F. M. (2014). Understanding "core practices" and "practice-based" teacher education: Learning from the past. Journal of Teacher Education, 65(4), 357-368.

Gainsburg, J. (2012). Why new mathematics teachers do or don't use practices emphasized in their credential program. Journal of Mathematics Teacher Education, 15(5), 359-379.

Goulding, M., Rowland, T., \& Barber, P. (2002). Does it matter? Primary teacher trainees' subject knowledge in mathematics. British Educational Research Journal, 28(5), 689-704.

Gresham, G. (2007). A study of mathematics anxiety in pre-service teachers. Early Childhood Education Journal, 35(2), 181-188.

Hoy, A. W., \& Spero, R. B. (2005). Changes in teacher efficacy during the early years of teaching: A comparison of four measures. Teaching and teacher education, 21(4), 343-356.

Klassen, R. M., Tze, V. M. C., Betts, S. M., \& Gordon, K. A. (2011). Teacher efficacy research 1998-2009: signs of progress or unfulfilled promise? Educational Psychology Review, 23(1), 21-43.

Ma, L. (1999). Knowing and teaching elementary mathematics: Teachers' understanding of fundamental mathematics in China and the United States. New York and London: Routledge.

Mason, J. (2014). Qualitative researching (2nd ed.). London: Sage Publication.

Morris, D. B., \& Usher, E. L. (2011). Developing teaching self-efficacy in research institutions: A study of award-winning professors. Contemporary Educational Psychology, 36(3), 232245.

Morris, D. B., Usher, E. L., \& Chen, J. A. (2016). Reconceptualizing the sources of teaching selfefficacy: a critical review of emerging literature. Educational Psychology Review, 1-39.

Moulding, L. R., Stewart, P. W., \& Dunmeyer, M. L. (2014). Pre-service teachers' sense of 
efficacy: Relationship to academic ability, student teaching placement characteristics, and mentor support. Teaching and teacher education, 41, 60-66.

Nolan, K. (2008). Imagine there's no haven: Exploring the desires and dilemmas of a mathematics education researcher. The psychology of mathematics education: A psychoanalytic displacement, 159-181.

Nolan, K. (2012). Dispositions in the Field: Viewing Mathematics Teacher Education Through the Lens of Bourdieu's Social Field Theory. Educational Studies in Mathematics, 80 (1-2), 201-216.

Peshkin, A. (1988). In search of subjectivity—one's own. Educational researcher, 17(7), 17-21.

Pfitzner-Eden, F. (2016). Why do I feel more confident? Bandura's sources predict preservice teachers' latent changes in teacher self-efficacy. Frontiers in Psychology, 7:1486.

Phelps, C. M. (2010). Factors that pre-service elementary teachers perceive as affecting their motivational profiles in mathematics. Educational Studies in Mathematics, 75(3), 293-309.

Poulou, M. (2007). Personal teaching efficacy and its sources: Student teachers' perceptions. Educational Psychology, 27(2), 191-218.

Rowland, T. (2013). The Knowledge Quartet: The Genesis and Application of a Framework for Analysing Mathematics Teaching and Deepening Teachers' Mathematics Knowledge. Sisyphus-Journal of Education, 1(3), 15-43.

Shulman, L. S. (1986). Those who understand: knowledge growth in teaching. Educational Researcher, 15(2), 4-14.

Skemp, R. R. (1976). Relational understanding and instrumental understanding. Mathematics Teaching, 77, 20-26.

Stylianides, A. J., \& Ball, D. L. (2008). Understanding and describing mathematical knowledge for teaching: Knowledge about proof for engaging students in the activity of proving. Journal of Mathematics Teacher Education, 11(4), 307-332.

Wah, W. K. (2007). Sources of influence on teacher self-Efficacy among preservice teachers. Paper presented at the Seminar Penyelidikan Pendidikan, Institut Perguruan Batu Lintang Tahun, Malaysia.

Wheatley, K. F. (2005). The case for reconceptualizing teacher efficacy research. Teaching and teacher education, 21(7), 747-766.

Woolfolk, A. E., \& Hoy, W. K. (1990). Prospective Teachers' Sense of Efficacy and Beliefs about Control. Journal of Educational Psychology, 82(1), 81-91.

Wyatt, M. (2014). Towards a re-conceptualization of teachers' self-efficacy beliefs: tackling enduring problems with the quantitative research and moving on. International Journal of Research \& Method in Education, 37(2), 166-189. 